\title{
PRELIMINARY STUDIES ON THE PREVALENCE AND CONTROLLING EFFICIENCY OF PASTEURIA PENETRANS, A PARASITE OF MELOIDOGYNE SPP. IN SRI LANKA
}

\author{
D.M. DE COSTA", H.N.P. WIJAYAGUNASEKARA, C.P. ALAHAKOON and \\ A.M. PRIYANTHA BANDARA \\ Department of Agricultural Biology, Faculty of Agriculture, University of \\ Peradeniya, Peradeniya.
}

(Received: 16 October 1996; accepted: 06 February 1998)

\begin{abstract}
Prevalence of Pasteuria penetrans in Sri Lanka was investigated and the effects of microenvironmental factors on its prevalence were determined. Naturally-occurring Pasteuria isolates were then evaluated for the efficiency of controlling Meloidogyne spp.. Randomly collected 804 soil samples were tested for the presence of Pasteuria using second stage juveniles of Meloidogyne. Controlling efficiency of Pasteuria was evaluated on greenhouse-grown tomato (Lycopersicon esculentum var. T-146) plants. Out of the tested soil samples, 26\% reported Pasteuria spores in varying concentrations. Microenvironmental factors such as soil drainage and cropping history showed a significant influence on the prevalence of Pasteuria whereas cropping pattern had no significant effect on its prevalence. However, the interaction between the cropping history and cropping pattern also had a significant effect on the prevalence of Pasteuria. Uncler greenhouse conditions, Pasteuria isolates showed $48 \%$ control of the nematode in tomato (var. T-146) and the root powder prepared from above tomato plants gave $8 \times 10^{5}$ spores/g root $(\mathrm{dw})$. Therefore, naturally-occurring $P$. penetrans isolates of the tested areas of Sri Lanka could be used as a potential biocontrol agent of Meloidogyne spp..
\end{abstract}

Key words: Biological control, Meloidogyne spp., Pasteuria penetrans, Rootknot nematodes.

\section{INTRODUCTION}

Root-knot nematodes (Meloidogyne spp.) are serious pests of many agriculturally-important crops grown in Sri Lanka. ${ }^{4,910}$ The pest can be controlled by cultural and chemical methods but these control measures are associated with practical limitations and environmentally-unfavourable effects.

Crop rotation has limited success in the control of root-knot nematodes and fallowing though effective for the control of the pest, would not be an economical option for the farmer. Use of nematicides is associated with many hazardous effects such as destruction of non-target organisms, contamination of ground water and bioaccumulation. Above all, small scale farmers are unable to afford the cost of chemical control of the nematodes. Therefore, biological control could

\footnotetext{
* Corresponding author.
} 
be considered as an alternative approach in managing root-knot nematodes and it can be effectively incorporated in the integrated management of the pest.

Pasteuria penetrans, has been identified as a promising biocontrol agent of Meloidogyne spp. by several workers. ${ }^{2,11,12}$ When the bacterium is added to soil in pots, small plots, container-grown crops and polytunnels, significant reduction of root-knot nematodes has been attained. ${ }^{5,67}$ Pasteuria is a soil inhabiting, mycelial and endospore-forming bacterium and has two modes of action against the Meloidogyne spp.. It can inhibit the egg production of adult female nomatode and the entry of the infective stage of the nematode into host roots. Therefore, a reduction in the nematode population over time can be seen.

Although the root-knot nematodes have been a problem in Sri Lanka for many decades, investigations so far conducted on potential biological control agents are limited. Therefore, the present study was conducted to investigate prevalence of $P$. penetrans in Sri Lanka, determine the effect of microenvironmental factors on its prevalence and evaluate the controlling efficiency of Meloidogyne spp. by naturally- occurring Pasteuria.

\section{METHODS AND MATERIALS}

\section{Experiment No. 1: Prevalence of $P$. penetrans and effect of micro- environmental factors}

\section{Experimental region}

Kandy District of Sri Lanka was selected as the region of investigation.

\section{Soil sampling}

A total of 804 soil samples were randomly collected from Kandy District. These soil samples represented all the Divisional Secretary Divisions (DSD) of Kandy District and at least five soil samples were taken from each Agricultural Instructors (AI) division which are the subdivisions of DSDs. Soil sampling was restricted only to upland areas. Approximately $200 \mathrm{~g}$ of soil was collected from a depth of $15 \mathrm{~cm}$ from the ground level.

\section{Additional information on the sampling site}

Microenvironmental factors which could have an influence on the growth and development of Meloidogyne and Pasteuria were recorded. The factors recorded were, cropping pattern (i.e. continuous or on and off cultivation), cropping history (i.e. for how long the same crop has been in a particular land) and drainage condition. 


\section{Detection of Pasteuria penetrans in soil}

Second stage juveniles $\left(\mathrm{J}_{2} \mathrm{~s}\right)$ were used to detect the Pasteuria spores in soil. ${ }^{13,16}$ $J_{2} \mathrm{~s}$ were initially isolated from the infected roots of several vegetable crop species collected from the fields at Marassana, Thalatuoya and Thannekumbura in Kandy District. After isolation $\mathrm{J}_{2} \mathrm{~S}^{8}$ were cultured on greenhouse-grown tomato plants (var. T-146).

Detection of Pasteuria in soil samples was done on plastic cylinders having $7.5 \times 7.5 \mathrm{~cm}$ dimensions. One end of the cylinder was sealed by a piece of muslin and a piece of paper towel was laid over it. Ten grams of soil was spread on the paper towel and approximately $15 J_{2} \mathrm{~s}$ were added on to the soil. Two-day-old $J_{2} \mathrm{~s}$ were used and they were free from pre-encumbered Pasteuria spores. These $J_{2} \mathrm{~s}$ were extracted after $24 \mathrm{~h}^{8}$ and examined under the light microscope (10x10) for spores attached on the cuticle. Soil samples which gave spore encumbered $J_{2} \mathrm{~s}$ were considered as Pasteuria positive soils. Average number of spores $/ J_{2}$ were recorded by examining 5 nematodes per extraction.

\section{Locating Pasteuria penetrans positive sites in maps}

Detailed maps of the 17 DSDs of Kandy District, provided by the Divisional Secretariats were used.

\section{Statistical analysis}

Effect of different microenvironmental factors on the prevalence of Pasteuria was determined by the chi-square test.

Experiment No. 2: Determining the efficiency of $P$. penetrans in controlling Meloidogyne spp.

\section{Experimental layout}

A greenhouse experiment was conducted in the Faculty of Agriculture, University of Peradeniya. Four-week old tomato plants (Lycopersicon esculentum var. T-146) were used as hosts of Meloidogyne and the following treatments were tested.

$\mathrm{T}_{1}=$ Plants inoculated with $\mathrm{J}_{2} \mathrm{~s}$ of Meloidogyne

$\mathrm{T}_{2}=$ Plants inoculated with $\mathrm{J}_{2} \mathrm{~s}$ of Meloidogyne pre-encumbered with $P$. penetrans spores

Approximately $100 \mathrm{~J}_{2}$ having an average of 4 spores/ $\mathrm{J}_{2}$ were inoculated into the rhizosphere. Spore encumbering was done by adding Meloidogyne $\mathrm{J}_{2} \mathrm{~S}$ 
into randomly selected Pasteuria positive soil samples obtained from Experiment No. 1. Each treatment was replicated 10 times and the plants were arranged according to a Completely Randomized Design. Plants were maintained at $28^{\circ} \mathrm{C}$ for 8 weeks and root systems were observed for the total nematode population. Spore concentration of $P$. penetrans in root powder and the \% nematode control by Pasteuria were also determined.

\section{Quantification of nematodes in the soil-root system}

Eight weeks after inoculation, second stage juveniles and male nematodes released into the soil were quantified by a soil extraction. ${ }^{8}$ The growth stages found in the root system (i.e. eggs, $J_{2} \mathrm{~s}, \mathrm{~J}_{3}+\mathrm{J}_{4} \mathrm{~s}$ and adult females) were quantified by staining the roots. ${ }^{1}$

\section{$\%$ control of nematode by Pasteuria}

Following formula was used for calculation

$\%$ control of nematode $=\frac{\mathrm{P}\left(\mathrm{T}_{1}\right)-\mathrm{P}\left(\mathrm{T}_{2}\right)}{\mathrm{P}\left(\mathrm{T}_{1}\right)} \times 100$

where;

$$
\begin{aligned}
\mathrm{P}\left(\mathrm{T}_{1}\right)= & \text { Total nematode population in the soil-root system } \\
& \text { under } \mathrm{T}_{1} \text { treatment } \\
\mathrm{P}\left(\mathrm{T}_{2}\right)= & \text { Total nematode population in the soil-root system under } \\
& \mathrm{T}_{2} \text { treatment }
\end{aligned}
$$

\section{Determining the Pasteuria spore concentration}

Dried root powder was prepared from $\mathrm{T}_{2}$ treated plants eight weeks after the inoculation of Meloidogyne. ${ }^{15}$ Dried root powder weighing $0.5 \mathrm{~g}$ was ground with $50 \mathrm{ml}$ water and the homogenate was filtered through a 38 micrometer sieve. The filtrate was observed using a haemocytometer (mag 10x40) to quantify the spore concentration.

\section{Statistical analysis}

The effect of Pasteuria in the reduction of Meloidogyne population was tested by ' $t$ ' test. 


\section{RESULTS}

\section{Experiment No.1: Prevalence of Pasteuria penetrans and the effect of microenvironmental factors}

Two hundred and seven (207) soil samples out of 804 (i.e. $26 \%$ ) collected from Kandy District reported. P. penetrans in varying concentrations (Figures 1 and 2).

Among the tested microenvironmental factors, cropping history and soil drainage showed a significant influence on the prevalence of Pasteuria $(p=0.05)$. Out of the total Pasteuria positive locations, $87 \%$ were obtained from wel]drained soils. Locations having longer cropping histories showed high \% prevalence of the biocontrol agent. Pasteuria were reported from $74 \%$ sampling sites which had more than 30 year cropping histories. In contrast, Pasteuria positive soils were reported only from $9 \%$ sampling sites which had a cropping history of less than 15 years. Cropping pattern in the sampling location did not show a significant effect on the prevalence of the biocontrol agent. However, the interaction between cropping history and cropping pattern had a significant effect on the prevalence of Pasteuria.

In the present study, high concentrations of Pasteuria were reported from locations under tea or mixed cropping cultivations, which had longer cropping histories (more than 30 years) and well-drained soils.

\section{Experiment No. 2: Efficiency of Pasteuria penetrans in controlling Meloidogyne spp.}

Numbers of different growth stages of Meloidogyne spp. found in $\mathrm{T}_{1}$ and $\mathrm{T}_{2}$ treatments are shown in Figure 3. No male nematodes were found in the tested samples.

Total nematode population of Meloidogyne spp. in $\mathrm{T}_{2}$ treatment was significantly lower than that of $T_{1}$ treatment. Significantly low number of eggs were found in Pasteuria treated root systems compared to the plants which were not treated with Pasteuria ( $\mathrm{p}=0.05)$. P. penetrans found from different locations of Kandy District gave 48\% control of the Meloidogyne spp. in greenhouse-grown tomato (var. $\mathrm{T}$-146) plants. Root powder prepared from $\mathrm{T}_{2}$ plants had an average spore concentration of $8 \times 10^{5}$ spores/g root. 


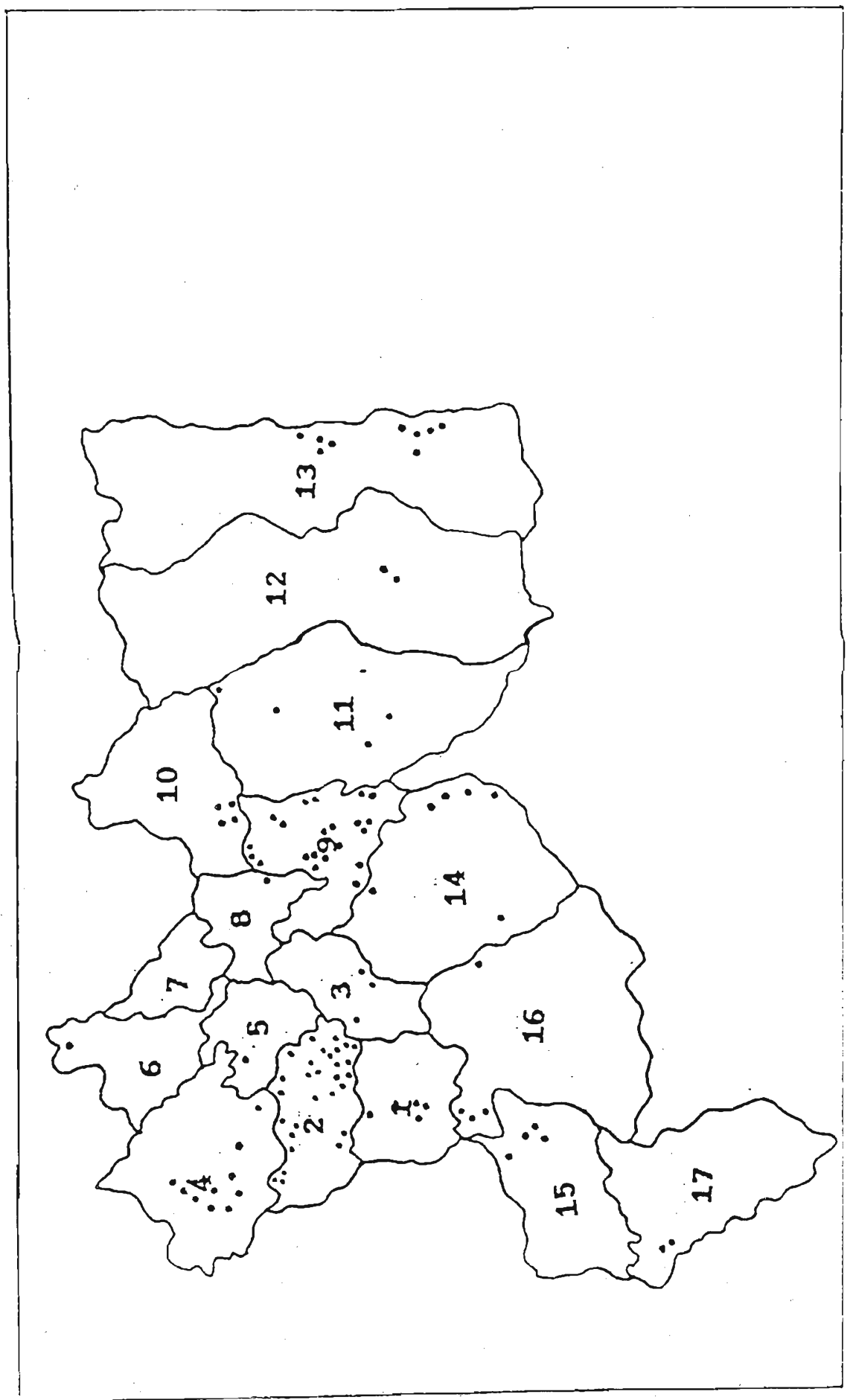

要 


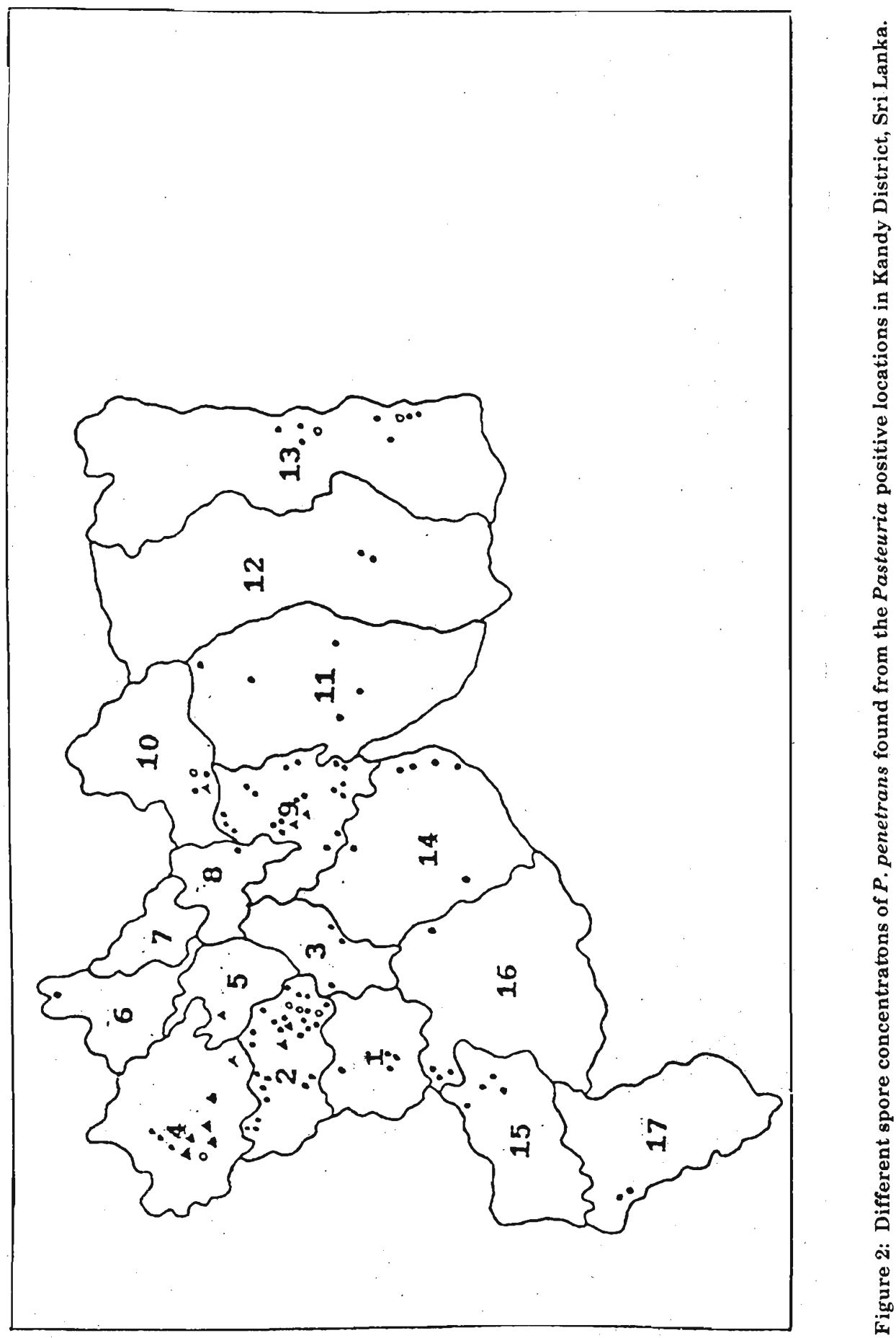




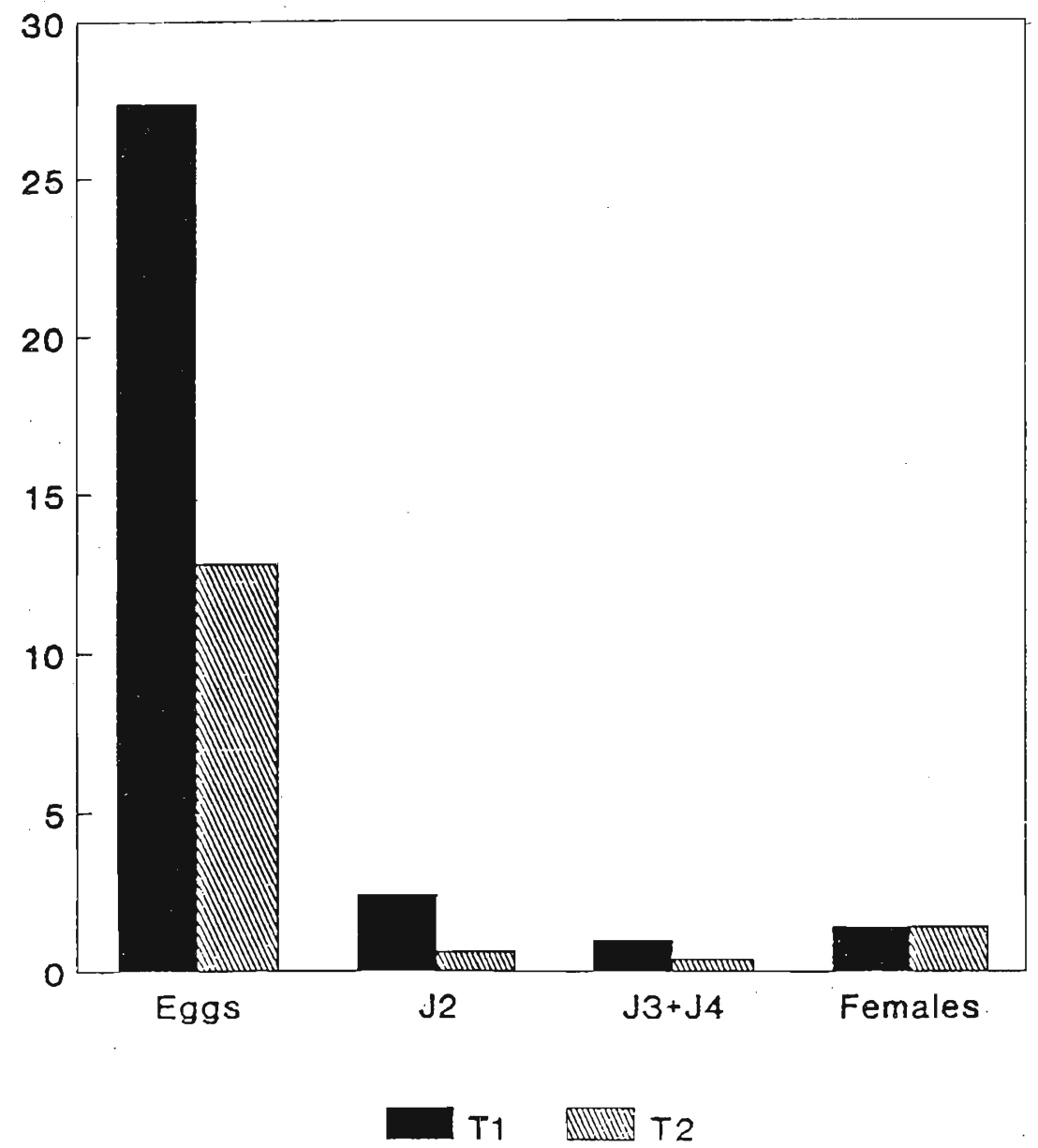

Figure 3: Mean number of different developmental stages of Meloidogyne spp/g root ( $\mathrm{fw}$ ) found in tomato (var. T-146) plant-root systems, 8 weeks after inoculation. $T_{1}=$ plants inoculated with $J_{2} \mathrm{~s}$ of Meloidogyne spp. $T_{2}=$ Plants inoculated with Pasteuria spore encumbered $\mathrm{J}_{2} \mathrm{~s}$ of Meloidogyne spp.

\section{DISCUSSION}

Prevalence of Pasteuria penetrans and effect of microenvironmental factors

P. penetrans is prevalent in many locations of Kandy District, Sri Lanka in varying concentrations. Most of the sampling sites reported adequate concentrations of spores to perform a successful infection of Meloidogyne. ${ }^{3}$ 


\section{Effect of microenvironmental factors}

Well-drained soils and longer cropping histories provide favourable growth and developmental conditions for the nematode and its obligate parasite, Pasteuria. ${ }^{14}$ Aerobic conditions in well-drained soils are conducive for the growth and development of the nematode and Pasteuria. Cropping histories of more than 30 years provide continuous availability of the hosts for the survival of both organisms. Similar observations have been reported from vineyards which had more than 25 year-cropping histories and it had been difficult to find Pasteuria in locations having less than 10 year cropping durations. ${ }^{16}$ In the present study also, high concentrations of Pasteuria were reported from perennial cropping systems having well-drained soils.

Since Pasteuria spores can survive in the soil for several years without losing their viability ${ }^{15}$ the effect of cropping pattern may not have an effect on its prevalence. Ability to infect a wide range of hosts by Meloidogyne would be the reason for the interaction between the cropping pattern and cropping history on the prevalence of Pasteuria.

\section{Controlling efficiency}

Pasteuria isolates of different locations of Kandy District, showed a 48\% control of the Meloidogyne spp. in tomato (var. T-146) under greenhouse conditions. However, the field performances of these isolates of Pasteuria could vary from the greenhouse condition.

\section{Spore concentration}

$P$. penetrans can reduce fecundity of Meloidogyne at concentrations as low as $1 \times 10^{4}$ spores/g soil and the number of root-knot nematodes invading roots is substantially reduced as the spore concentration approaches $1 \times 10^{5}$ spores $/ \mathrm{g}$ soil. 5,17 Since the spore concentration of the root powder obtained from the present study was $1 \times 10^{5}$ spores/g root (dry weight) an effective contro] of the nematode could be obtained.

\section{Potential use in an Integrated Management Programme}

Present study revealed the presence of $P$. penetrans, in many locations of the Kandy District. Further indepth studies are essential to investigate the field performance of the biological control agent under local environmental conditions. P.penetrans can be introduced and once introduced, the biocontrol agent will get augmented in the fields provided the availability of the host plants. ${ }^{14}$ Therefore, microenvironmental factors which favour the gradual increase of the biocontrol agent can be promoted to enhance the naturally-inhabiting populations 
of Pasteuria. Future investigations have to be focused on the determination of ecological factors which are conducive for the biological control by Pasteuria. It will be helpful to develop an integrated management programme especially for small-scale vegetable cultivations which are being heavily infested with Meloidogyne spp. at present.

\section{Acknowledgement}

We thank staff of the Department of Agriculture and the Divisional. Secretariats in Kandy District for their assistance.

\section{References}

1. Bridge J., Page S. \& Jordan S. (1982). An improved method or staining: nematodes in roots. part 1, pp. 171. Report of the Rothamstead Experimental Station, London.

2. Brown S.M., Kepner J.L. \& Smart G.C. (1985). Increased crop yields following application of Bacillus penetrans to field plots infested with $M$. incognita. Soil Biology and Biochemistry 17: 483-486.

3. Davies K.G., Kerry B.R. \& Flynn C.A. (1988). Observations on the pathogenicity of Pasteuria penetrans, a parasite of root-knot nematodes. Annals of Applied Biology 112: 491-501.

4. Ekanayake H.M.R.K. (1986). Important parasitic nematodes associated with horticultural crops in Sri Lanka. Progress and Abstracts. Annual Research Conference. Research Division. Department of Agriculture, Peradeniya.

5. Gowen S.R., Channer A.C. \& Hague N.M.G.( 1989). The control of root-knot nematodes with Pasteuria penetrans. Journal of Nematology 21: 563.

6. Gowen S.R. \& Ahmed R. (1990). Pasteuria penetrans for control of pathogenic nematodes. Aspects of Applied Biology 24: 25- 31.

7. Gowen S.R. \& Tzortzakakis E.A. (1994). Biological control of Meloidogyne spp. with Pasteuria penetrans. Bulletin OEPP/EPPO 24: 495-500.

8. Hooper D.J. (1985). Extraction of free living stages from soil. In: Laboratory methods for work with plant and soil nematodes. (Ed. J.F. Southey) pp. 530. HMSO, London. 
9. Lamberti F., Ekanayake H.M.R.K. \& Divito M. (1979). The root-knot nematodes (Meloidogyne spp.) found in Sri Lanka. FAO Plant Protection Bulletin 35(1): 27-31.

10. Lamberti F. \& Ekanayake H.M.R.K. (1981). Nematode problems in agricultural crops in Sri Lanka. Technical report Government of Sri Lanka under FAO/DOA Plant Protection. 36pp.

11. Mankau R. (1975). Bacillus penetrans n. comb. causing a virulent disease of plant parasitic nematodes. Journal of Invertebrate Pathology 26: 333-9.

12 Ratnasoma H.A., Gowen S.R. \& Wijekoon S. (1991). Evaluations of some potential methods for control of root-knot nematodes in black pepper. Tropical Agriculturist 147: 135-141.

13. Stirling G.R. (1984). Biological control of Meloidogyne javanica with Bacillus penetrans. Phytopathology 74: 55-60.

14. Stirling G.R. (1991). Biological control of plant parasitic nematodes:progress, problems and prospects. 282 pp. CAB international, Wallingford.

15. Stirling G.R. \& Wachtel M.F. (1980). Mass production of Bacillus penetrans for the biological control of root-knot nematodes. Nematologica 26: 308-12.

16. Stirling G.R. \& White A.M. (1982). Distribution of a parasite of root-knot nematodes in South Australian vineyards. Plant Disease 66: 52-3.

17. Stirling G.R., Sharma R.D. \& Perry J. (1990). Attachment of Pasteuria penetrans spores to Meloidogyne javanica and its effects on infectivity of the nematode. Nematologica 36: 246-52. 